\title{
Renal cell carcinoma with secondary hemophagocytic syndrome: A case report
}

\author{
Chia-Ter Chao, MD; ${ }^{*}$ Chih-Chin Kao, MD; ${ }^{*}$ Szu-Ying Lee, MD;* Shu-Jung Ho, MD; ${ }^{*}$ Ying-Jheng Jhuang, MD;* \\ Lars Hung-Yuan Li, MD; ${ }^{\dagger}$ Tze-Wah Kao, MD*
} *Division of Nephrology, Department of Internal Medicine, National Taiwan University Hospital and College of Medicine, National Taiwan University, Taipei, Taiwan; 'Division of Endocrinology, Department
of Internal Medicine, National Taiwan University Hospital and College of Medicine, National Taiwan University, Taipei, Taiwan

Cite as: Can Urol Assoc J 2012;6(2):e64-66. http://dx.doi.org/10.5489/cuaj.10188

\section{Abstract}

A patient with a suspected malignancy and pancytopenia warrants much consideration. Most clinicians would consider bone marrow infiltrative process, heralding a grave prognosis. However, rare occurrence of hemophagocytic lymphohistiocytosis is another diagnostic possibility we should keep in mind. The treatment choices and overall prognosis may differ from patients without hemophagocytosis. We present a case of incidentally found advanced renal cell carcinoma (RCC) concurrent with hemophagocytosis process in the bone marrow. We also discuss the importance of this finding.

\section{Case report}

A 67-year-old man was referred to our emergency department due to exertional dyspnea for weeks. He had a medical history of hypertension without regular control. On arrival, his vital sign was stable with blood pressure 150/92 mmHg. Physical examination disclosed pale conjunctiva and cachetic limbs. His abdomen was distended, with a palpated mass at the right of umbilicus. Hemogram revealed prominent anemia $(7.6 \mathrm{~g} / \mathrm{dL})$, thrombocytopenia $(16000 / \mu \mathrm{L})$ and normal leukocyte count $(4200 / \mu \mathrm{L})$. Mildly impaired renal function was noted on biochemistry profile (serum creatinine $125 \mu \mathrm{mol} / \mathrm{L}$ ). An abdominal computed tomography (CT) without contrast showed an 8-cm right-sided renal mass with central necrosis (Fig. 1), as well as a right lung nodule. We did not administer contrast enhancement due to expected worsening renal function. His bicytopenia was refractory to component therapy, and bone marrow smear demonstrated hypercellularity with multiple foci of histiocytes engulfing blood cell components, including erythrocytes, leukocytes and platelets (Fig. 2). The pathologic picture is compatible with the diagnosis of hemophagocytic lymphohistiocytosis.
Autoimmune markers, including antinuclear antibody and complement levels, were normal, as was viral serology, such as hepatitis virus, Epstein-Barr virus (EBV) and cytomegalovirus (CMV). Therapy with intravenous immunoglobulin (IVIG) and pulse cyclophosphamide was ineffective to him, and his bicytopenia progressed. Ultrasound-guided tumour biopsy was performed after aggressive component therapy to restore platelet level. Histopathologic examination showed foci of cells with clear and bubbled-cytoplasm staining strongly for cytokeratin $(\mathrm{CK})$ and CD10, indicating clear cell renal cell carcinoma (RCC) (Fig. 3). Flow cytometry of both the tumour fragments, as well as the bone marrow sample, were negative for abnormal clonal lymphocyte proliferation, and no CK-positive cells were found in the bone marrow. Spiking fever ensued several days after tumour biopsy, and an empirical antibiotic was prescribed for presumed hospital acquired infection. However, hypoxemic respiratory failure occurred, and the patient died a few days later despite aggressive treatment.

RCC ranks seventh among all malignant tumours. It occupies about $4 \%$ of the annual new cases of malignancy in the United States and Canada, with up to 30000 to 40000 new cases per year. ${ }^{1}$ The incidence is slowly rising, probably owing to the increased use of imaging and screening, ${ }^{2}$ but the 5-year survival also improves (up to 69\%) due to earlier detection. The classic triad of hematuria, flank pain and abdominal mass presents in about $20 \%$ to $30 \%$ of patients only, and up to $50 \%$ patients have no symptoms. ${ }^{3}$ Like our patient, $15 \%$ of patients are diagnosed at stage IV and no effective chemotherapy exists to combat these advanced tumours. The overall survival, however, improves from 10 to 40 months after the advent of target therapy (i.e., sunitinib and sorafenib).

About one-third patients with RCC report constitutional symptoms, such as fever, weight loss and malaise, while paraneoplastic syndromes occur in another third of patient. ${ }^{4}$ Among these syndromes, polycythemia, hypertension and leukocytosis are the most common. The possible mechanism of constitutional symptoms and leukocytosis includes aberrant cytokine production. ${ }^{5}$ Animal studies have consist- 


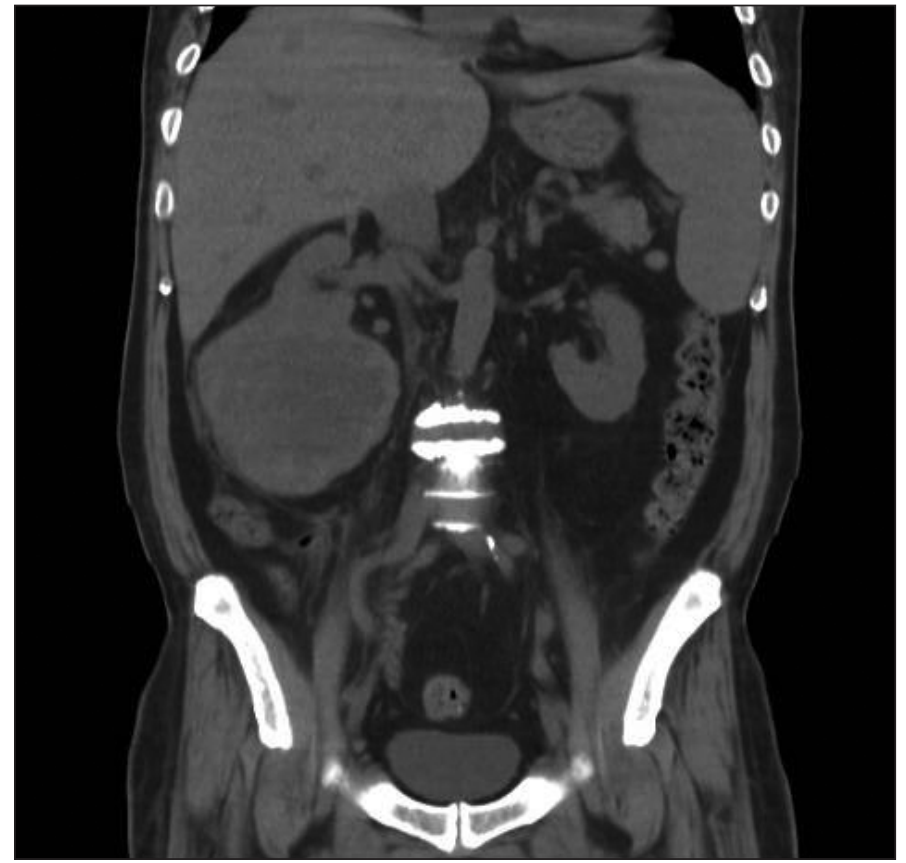

Fig. 1. Abdominal computed tomography (CT) without contrast demonstrating large tumor with central hypodensity within right kidney lower pole, compatible with necrosis.

ently indicated that the cytokine orchestra of tumour necrosis factor- $\alpha$ (TNF- $\alpha$ ), interleukin-1 (IL-1), interleukin-6 (IL-6) and interferon $\gamma$ results in cachexia; interferon $\gamma$ suppressed appetite along with other tumour-secreted molecules. ${ }^{6}$

Hemophagocytic lymphohistiocytosis is traditionally divided into familial (genetic) and acquired form, and plenty of names have been attributed since its first inception in 1979. It is originally known as virus-associated hemophagocytic syndrome (VAHS). ${ }^{7}$ The precipitating events include bacterial, fungal, protozoal, rheumatologic diseases, such as lupus and adult onset Still's disease. Malignancy-associated hemophagocytosis is another rare entity of the syndrome, mostly involving lymphoma. ${ }^{8}$ To the best of our knowledge, solid tumour association has only been documented in nonseminomatous germ cell tumour, rhabdomyosarcoma, lung and breast adenocarcinoma, ${ }^{9,10,11}$ but never in RCC. The mechanism is unclear, but extrapolating from familial form, deranged cytokine interaction between histiocytes, cytotoxic T-cells and natural killer (NK) cells due to defective perforin ${ }^{12}$ and other cytotoxic molecules would be the best explanation. The concerted cytokine reaction includes high level of Interferon $\gamma$, IL-6, IL-8, IL-12 and TNF- $\alpha$ churning in a defective environment with failure of effector cells to eliminate pathogens. A perforin knock-out mouse model with hemophagocytosis indicates a pivotal role of interferon $\gamma .{ }^{13}$ The devastated cytokine storm between RCC and secondary hemophagocytosis in our patient illustrates a rare coincidence of these two disorders. However, the exact interaction would require more understanding of tumour biology and the immune reaction toward malignancies.

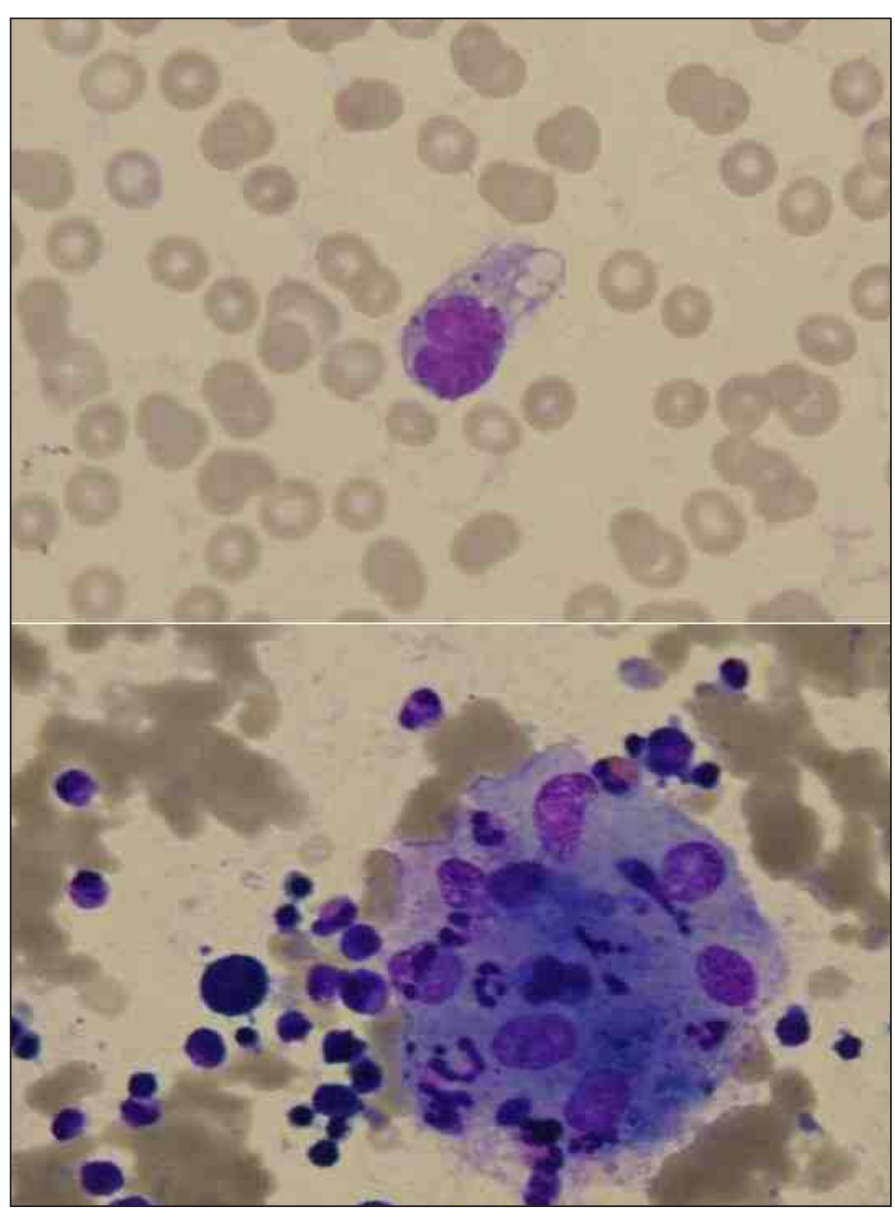

Fig. 2. (Upper) Peripheral blood smear showing suspicious histiocyte engulfing blood cells; (Lower) Bone marrow smear showing hemophagocytic process with histiocyte phagocytosing leukocyte and erythrocytes.

The treatment of hemophagocytosis in our patient was hampered by the absence of tissue proof initially, and we chose IVIG and pulse cyclophosphamide in the hope of ending this vicious cycle. The traditional regimen of highdose steroid was not chosen due to the patient's elevated gastrointestinal bleeding risk. Recent reports about successful etoposide treatment in EBV-related hemophagocytosis are encouraging, but the mechanism includes etoposide interference of EBV nuclear antigen synthesis and cell transformation, which would not be expected to occur in our patient, whose EBV serology was negative. There was also no evidence of RCC metastasis in our patient's bone marrow cavity, so hemophagocytic acitivity was not believed to result from tumour behavior. The rapidity of his clinical deterioration further signified the dismal prognosis without primary tumour control. Standard immunotherapy or novel biologic agent was not given to the patient because of the speed of his deterioration; however, these agents would potentially be of help in some cases.

In Turkey, a nationwide multicentre study in pediatric patients with malignancy-associated hemophagocytosis included 29 reported cases, the largest case series identi- 
Chao et al.

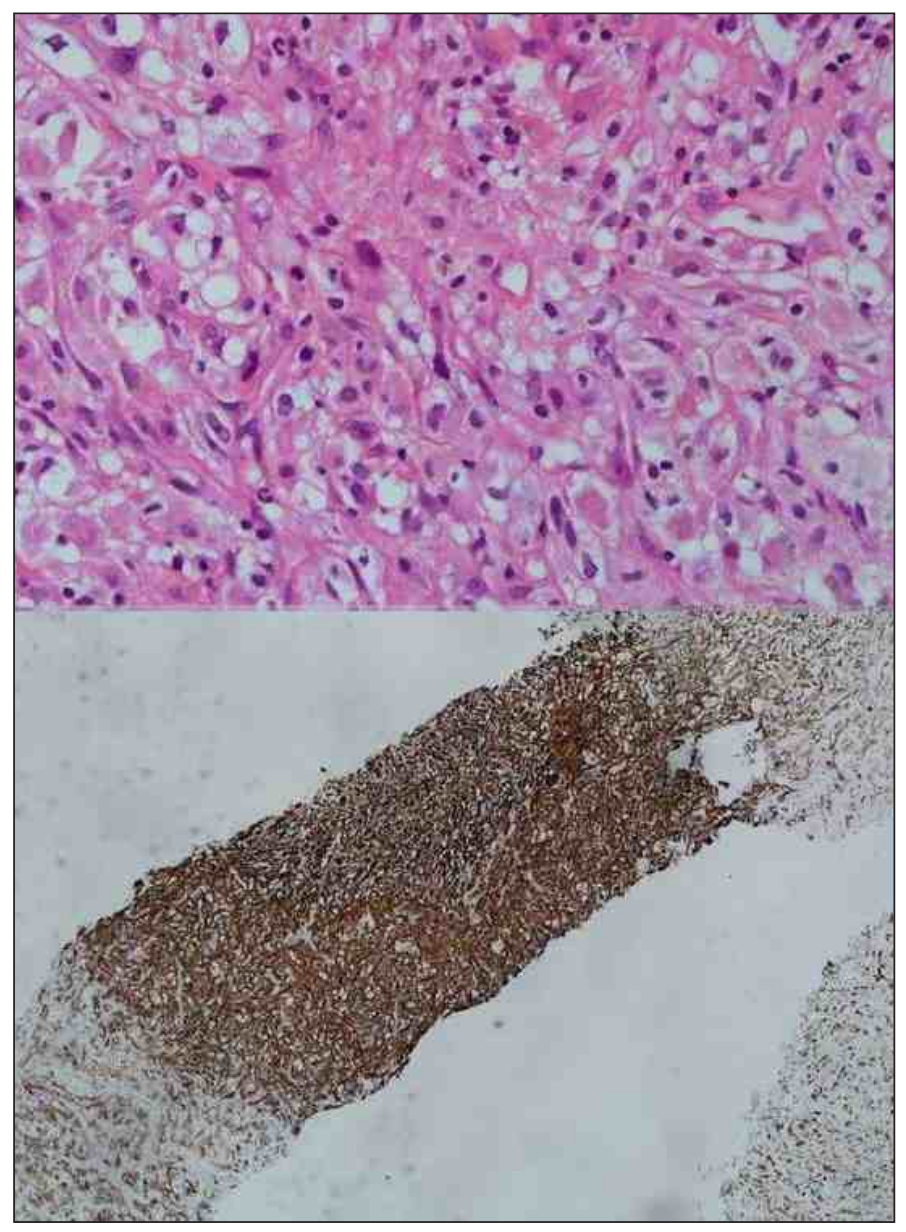

Fig. 3. (Upper) Tumor biopsy showed atypical cells with bubbly cytoplasm, compatible with clear cell renal cell carcinoma; (Lower) The neoplastic component staining strongly for cytokeratin (CK), confirming renal cell origin.

fied..$^{14}$ Of these cases, $34.5 \%$ received IVIG only, $7 \%$ received corticosteroid only, and $51.7 \%$ patients did not receive any treatment. One of these patients underwent a protocolbased regimen, according to hereditary lymphohistiocytic hemophagocytosis group trial (HLH-2004). The results of this study show that fever and pancytopenia respond favorably to either IVIG or corticosteroid, but the overall case mortality rate is still about one third. Etoposide-based regimen has also been rarely reported to be effective in germ cell tumourrelated acquired hemophagocytic syndrome. ${ }^{9}$ However, it is crucial that the underlying malignancy is controlled, since pharmacological or surgical tumour control is documented to provide fair pancytopenia reversal.

\section{Conclusion}

RCC and hemophagocytosis, two events with cytokine secretion and storming, rarely occur. Specific therapy directed against this rare disease has not been established, and anecdotal evidence suggests corticosteroid or IVIG may be effective. Etoposide is also another promising regimen. Our case further elucidates the pathophysiology and contributes to our understanding of cytokine interaction and, possibly, normalizing the immunologic response.

Competing interests: None declared.

This paper has been peer-reviewed.

\section{References}

1. Jemal A, Siegel R, XU J, et al. Cancer Statistics, 2010. CA Cancer J Clin 2010;60:277-300. http:// dx.doi.org/10.3322/caac.20073

2. Pantuck AJ, Zisman A, Belldegrun AS. The Changing Natural History of Renal Cell Carcinoma. J Urol 2001;166:1611-23. hittp://dx.doi.org/10.1016/50022-5347(05)65640-6

3. Miller DC, Ruterbusch J, Colt JS, et al. Contemporary Clinical Epidemiology of Renal Cell Carcinoma: Insight from a Population Based Case-control Study. J Urol 2010;184:2254-8. http://dx.doi.org/10.1016/i. juro.2010.08.018

4. Sacco E, Pinto F, Sasso F, et al. Paraneoplastic Syndromes in Patients with Urological Malignancies. Urol Int 2009;83:1-11. http://dx.doi.org/10.1159/000224860

5. Szlosarek PW, Balkwill FR. Tumour necrosis factor $\alpha$ : a potential target for the therapy of solid tumours. Lancet Oncol 2003;4:565-73. http://dx.doi.org/10.1016/S1470-2045(03)01196-3

6. Tisdale MJ. Cachexia in Cancer Patients. Nat Rev Cancer 2002;2:862-71. http://dx.doi.org/10.1038/ nrc927

7. Risdall RJ, Mckenna RW, Nesbit ME, et al. Virus-associated hemophagocytic syndrome: a benign histiocytic proliferation distinct from malignant histiocytosis. Cancer 1979;44:993-1002. http://dx.doi. org/10.1002/1097-0142(197909)44:3<993::AID-CNCR2820440329>3.0.C0;2-5

8. Janka GE. Hemophagocytic syndromes. Blood Rev 2007;21:245-3. http://dx.doi.org/10.1016/i. bre.2007.05.001

9. Sada E, Shiratsuchi M, Kiyasu J, et al. Primary Mediastinal Non-seminomatous Germ Cell Tumor Associated with Hemophagocytic Syndrome. J Clin Exp Hematopathol 2009;49:117-20. http://dx.doi. org/10.3960/islrt.49.117

10. Tsoi WC, Feng CS. Hemophagocytosis by Rhabomyosarcoma Cells in Bone Marrow. Am I Hematol 1997;54:340-2. http://dx.doi.org/10.1002/(SICI) 1096-8652 (199704)54:4<340::AIDAJHI7 >3.0.CO;2-F

11. Molad Y, Stark P, Prokocimer M, et al. Hemophagocytosis by Small Cell Lung Carcinoma. Am J Hematol 1991;36:154-6. http://dx.doi.org/10.1002/aih.2830360218

12. Stepp SE, Dufoureq-Lagelouse $R$, Le Deist $D$, et al. Perforin gene defects in familial hemophagocytic lymphohistiocytosis. Science 1999;286:1957-9. http://dx.doi.org/10.1126/science.286.5446.1957

13. Jordan MB, Hildeman D, Kappler J, et al. An animal model of hemophagocytic lymphohistiocytosis (HLH): CD8+ T cells and interferon gamma are essential for the disorder. Blood 2004;104:735-43. http:// dx.doi.org/10.1182/blood-2003-10-3413

14. Celkan T, Berrak S, Kazanci E, et al. Malignancy-associated hemophagocytic lymphohistiocytosis in pediatric cases: a multicenter study from Turkey. Turk J Pediatr 2009;51:207-13.

Correspondence: Dr. Tze-Wah Kao, Division of Nephrology, Department of Internal Medicine, National Taiwan University Hospital, NNo. 7, Chung-Shan South Road, 100 Taipei, Taiwan, Republic of China; twka02@ntuh.gov.tw 